\title{
A dimensão afetiva no processo de alfabetização de jovens e adultos
}

\author{
The affective dimension in the Youth and adult literacy process \\ La dimensión afectiva en el proceso de alfabetización de jóvenes y adultos
}

Recebido: 03/03/2021 | Revisado: 12/03/2021 | Aceito: 19/03/2021 | Publicado: 27/03/2021

\author{
Joselia Cristina Siqueira da Silva \\ ORCID: https://orcid.org/0000-0003-2448-9886 \\ Universidade Federal do Paraná, Brasil \\ E-mail: jcristinaquimica@gmail.com \\ Gilmene Bianco \\ ORCID: https://orcid.org/0000-0002-2654-5370 \\ Universidade Federal do Espírito Santo, Brasil \\ E-mail: gilmeneb@yahoo.com.br \\ Dieison Prestes da Silveira \\ ORCID: https://orcid.org/0000-0002-8446-4157 \\ Universidade Federal do Paraná, Brasil \\ E-mail: dieisonprestes@gmail.com \\ Rodrigo Da Vitória Gomes \\ ORCID: https://orcid.org/0000-0002-7171-695X \\ Universidade Federal do Paraná, Brasil \\ E-mail: rodrigodavitoriagomes@gmail.com \\ Deivid Jonas Silva da Veiga \\ ORCID: https://orcid.org/0000-0002-1625-0560 \\ Universidade de Cruz Alta, Brasil \\ E-mail: deividveiga96@gmail.com \\ Denise da Costa Dias Scheffer \\ ORCID: https://orcid.org/0000-0002-1755-542X \\ Universidade de Cruz Alta, Brasil \\ E-mail: dcdscheffer@gmail.com
}

\begin{abstract}
Resumo
A afetividade tem um papel importante no processo de aprendizagem do ser humano. Com o auxílio da afetividade, docentes e educandos conseguem criar laços de amizade entre si. A mesma potencializa o ser humano a revelar os seus sentimentos em relação a outros seres e objetos. Partindo desses pressupostos, o presente artigo tem por objetivo discorrer uma análise sobre a importância do aspecto afetivo e da interação social vivenciada pelos jovens e adultos em sala de aula durante o processo de alfabetização. Esta pesquisa apresenta metodologia de natureza qualitativa dentro de uma perspectiva bibliográfica exploratória, no qual os dados denotados foram analisados com base na perspectiva do Método da Análise Documental, que constitui na extração de elementos informativos de um documento original a fim de expressar seu conteúdo de forma abreviada, resultando na conversão de um documento primário em documento secundário. Nos dados obtidos infere-se que as relações estabelecidas em sala de aula constituem um dos momentos mais significativos para a expressão da afetividade, contribuindo, assim, para o desenvolvimento da constituição do aluno como pessoa.
\end{abstract}

Palavras-chave: Afeto; Âmbito escolar; Interação social; Alfabetização; EJA.

\begin{abstract}
Affection has an important role in the human being's learning process. With the help of affection, teachers and students are able to create bonds of friendship with each other. It empowers the human being to reveal his feelings in relation to other beings and objects. Based on these assumptions, this article aims to discuss an analysis of the importance of the affective aspect and social interaction experienced by young people and adults in the classroom during the literacy process. This research presents a qualitative methodology within an exploratory bibliographic perspective, in which the denoted data were analyzed based on the perspective of the Document Analysis Method, which consists in extracting informational elements from an original document in order to express its content in a abbreviated, resulting in the conversion of a primary document into a secondary document. In the data obtained, it can be inferred that the relationships established in the classroom constitute one of the most significant moments for the expression of affectivity, thus contributing to the development of the student's constitution as a person.
\end{abstract}

Keywords: Affection; School scope; Social interaction; Literacy; EJA. 


\begin{abstract}
Resumen
El afecto tiene un papel importante en el proceso de aprendizaje del ser humano. Con la ayuda del afecto, profesores y alumnos pueden crear lazos de amistad entre ellos. Faculta al ser humano a revelar sus sentimientos en relación con otros seres y objetos. A partir de estos supuestos, este artículo tiene como objetivo discutir un análisis de la importancia del aspecto afectivo y la interacción social que viven jóvenes y adultos en el aula durante el proceso de alfabetización. Esta investigación presenta una metodología cualitativa dentro de una perspectiva bibliográfica exploratoria, en la cual los datos denotados fueron analizados con base en la perspectiva del Método de Análisis de Documentos, que consiste en extraer elementos informativos de un documento original con el fin de expresar su contenido en forma abreviada, resultando en la conversión de un documento principal en un documento secundario. De los datos obtenidos se puede inferir que las relaciones que se establecen en el aula constituyen uno de los momentos más significativos para la expresión de la afectividad, contribuyendo así al desarrollo de la constitución del alumno como persona.
\end{abstract}

Palabras clave: Afecto; Alcance de la escuela; Interacción social; Literatura; EJA.

\title{
1. Introdução
}

A aprendizagem é um processo contínuo que ocorre durante toda a vida do indivíduo. O desenvolvimento do processo cognitivo será resultado de suas potencialidades genéticas, assim como as possíveis habilidades desenvolvidas ao longo de todas as fases da vida (Jarvis, 2013). O processo de aprendizagem relaciona-se com a interação do indivíduo com o meio ao qual está inserido, envolvendo uma compreensão abrangente do aprender, indo além do espaço restrito escolar. Todo sujeito encontra-se em contextos extensivos que podem interferir na aprendizagem, necessitando assim que os mesmos sejam levados em consideração durante o processo de ensino.

Com isso, podemos inferir que a aprendizagem se constitui de um processo de formação humana perpassada por uma produção autônoma do conhecimento, promovendo a democratização dos saberes e relacionando o indivíduo criticamente na sociedade ao qual está inserido. O espaço escolar, é essencial na formação dos indivíduos de uma comunidade. O mesmo exerce o papel de contribuir não só na aquisição de conhecimentos no campo cognitivo, mas também na construção da personalidade dos educandos.

Segundo Wallon (1972), duas funções básicas constituem a personalidade: afetividade e inteligência. A afetividade relaciona-se às sensibilidades internas e se orienta em direção ao mundo social e para a construção da pessoa; a inteligência, por sua vez, vincula-se às sensibilidades externas e está voltada para o mundo físico, para a construção do objeto. As relações entre conhecimento e afetividade se fazem presentes na empatia, na curiosidade capaz de fazer o indivíduo avançar em suas hipóteses no processo de desenvolvimento e aprendizagem. Diante desse pensamento a razão e emoção não se dissociam, visto que uma não acontece sem a outra.

Afetividade é a capacidade individual de experimentar o conjunto de fenômenos afetivos, emoções, paixões e sentimentos. Assim, Codo e Gazzotti (1999, p. 48) escreve:

"conjunto de fenômenos psíquicos que se manifestam sob a forma de emoções, sentimentos e paixões, acompanhados sempre de impressão de dor ou prazer, de satisfação ou insatisfação, de agrado ou desagrado, de alegria ou de tristeza".

No contexto escolar, segundo Freire (1996), existe uma relação importante em que a afetividade se faz real, que é entre a alegria e a esperança, pois “a esperança de que professor e alunos juntos podemos aprender, ensinar, inquietar-nos, produzir e juntos igualmente resistir aos obstáculos à nossa alegria" (Freire, 1996, p. 29). Assim, quando a afetividade está presente na relação entre o educador e o educando, há um processo facilitador na construção do conhecimento.

Tendo em vista que na sala de aula da EJA há realidades distintas e uma heterogeneidade entre os alunos, é necessário que se oportunize possibilidades de ensino que beneficiem "um ambiente favorável para os alunos, visando ao estabelecimento de vínculos de aproximação com os conteúdos e práticas desenvolvidos” (Leite, 2012, p. 83-84).

Para criar essas condições, é imprescindível que o educador conheça as especificidades dos alunos inseridos na EJA, 
ressaltando em sua maioria os alunos dessa modalidade chegam à escola em condições que não favorecem a ida à escola, após anos fora da sala de aula, com responsabilidades profissionais e familiares, entre outros. Para a aquisição do conhecimento, a afetividade na relação professor-aluno na EJA proporciona oportunidades para minimizar as dificuldades que são encontradas dentro do âmbito escolar.

Pensando na importância de debates e reflexões acerca da aprendizagem humana, este manuscrito tem como objetivo discorrer sobre a importância do aspecto afetivo e da interação social vivenciada pelos jovens e adultos em sala de aula durante o processo de alfabetização.

\section{Metodologia}

A metodologia abordada nessa pesquisa apresenta natureza qualitativa dentro de uma perspectiva bibliográfica exploratória. A pesquisa exploratória tem por objetivo aprimorar hipóteses e proporcionar familiaridade com o campo de estudo. A mesma institui a primeira etapa de um estudo mais amplo e é utilizada em pesquisas cujo tema foi pouco explorado, podendo ser aplicada em estudos iniciais para se obter uma visão geral acerca de determinados fatos (Gil, 2002). Os dados denotados foram analisados com base na perspectiva do Método da Análise Documental, que constitui na extração de elementos informativos de um documento original a fim de expressar seu conteúdo de forma abreviada, resultando na conversão de um documento primário em documento secundário (Ludke \& André, 1986).

\section{A Construção do Indivíduo a Partir da Afetividade}

A construção de conhecimento na escola se dá a partir da relação entre o sujeito e o objeto, tendo como principal mediador o professor. As relações que vão sendo estabelecidas não envolvem apenas a cognição, mas "também são marcadamente afetivas" (Leite, 2012, p. 50).

A afetividade no desenvolvimento humano, especialmente no processo de ensino, envolve o acreditar que o educando é capaz de se tornar uma pessoa mais autônoma nas resoluções de problemas e ser socialmente participativo ao interagir com a sociedade. Uma convivência baseada no respeito e uma relação afetiva positiva entre professor e aluno colabora no processo de desenvolvimento e aprendizagem do aluno.

Wallon (1972) relata a importância da afetividade no desenvolvimento humano. $\mathrm{O}$ autor corrobora na afirmação que o ser humano desde o seu nascimento é envolvido pela afetividade e que o afeto desempenha um papel fundamental em seu desenvolvimento e no estabelecimento de boas relações sociais. $\mathrm{O}$ autor relata que o movimento é a base do pensamento e das emoções que dão origem a afetividade, sendo ela fundamental na construção do sujeito. Para exemplificar essa teoria, Wallon ilustrou esse pensamento relatando que um bebê quando está com fome ou dor de barriga chora para manifestar sua vontade, mesmo não tendo como se expressar pela fala ele induz a mãe a tentar entender sua necessidade. Com isso, o bebê simboliza através de suas reações o afeto que necessita.

Ensinar não é apenas repassar conteúdo, é possibilitar ao educando a tomar consciência de si, dos outros, da sociedade em que se vive e também do seu papel dentro da sociedade. No contexto escolar, a interação entre aluno e professor favorece o desenvolvimento e o aprendizado. Gestos como um sorriso, uma escuta ativa e uma atitude respeitosa são fundamentais quando o educador investe na afetividade na relação professor- aluno, tais elementos contribuem para a adaptação do educando, assim como a segurança, o conhecimento e o desenvolvimento do mesmo.

Pensar sobre afetividade no processo de ensino é contribuir para uma sociedade escolar mais justa e solidária, é refletir sobre os valores e os afetos que fazem diferença na dinâmica da escola. A evolução de um indivíduo não depende somente da capacidade intelectual garantida pelo caráter biológico, o meio ambiente também condiciona a evolução, permitindo ou impedindo que determinadas potencialidades sejam desenvolvidas. O desenvolvimento ocorre através de vários 
estágios, e nesses estágios, a inteligência e a afetividade vão alternando em termos de importância (Almeida \& Mahoney, 2007).

No âmbito escolar, a afetividade vai além dos cuidados, os abraços, os carinhos, pois envolve, principalmente, a partilha de saberes e experiências, as amizades, o respeito com o outro, à cultura, a busca do conhecer e entender as dificuldades dos alunos, o despertar no outro o interesse em aprender, tornando-a, assim, um elemento indispensável no processo de ensino-aprendizagem. Vieira, (2004, p. 9) explana que:

"A afetividade é a capacidade de provocar mudanças no outro a partir de sentimentos despertados nele através da interação e da troca de experiências. Ela pode fazer com que o educando apaixone-se pelo conhecimento e descubra o prazer em aprender correlação entre a dimensão cognitiva e afetiva é de suma importância no processo educativo, pois auxiliará no desenvolvimento da aprendizagem do aluno".

Paralelo a esse pensamento, Luck e Carneiro (1985, p. 23) afirmam que "a identificação da correlação entre os domínios afetivo e cognitivo são do maior interesse para a educação, uma vez que, por meio dela, se poderá melhor influir sobre a promoção do desenvolvimento integral do aluno".

De acordo com Almeida e Mahoney (2007), Wallon distribui o papel da afetividade em estágios que passam a se expressar através de suas características histórica e cultural ao longo do desenvolvimento do ser humano. Neste sentido, Almeida \& Mahoney (2007, p. 19), destacam a seguir a afetividade presente na fase da adolescência e da vida adulta:

"Estágio puberdade e adolescência (11 anos em diante) - aparece aqui a exploração de si mesmo, na busca de uma identidade autônoma, mediante atividades de confronto, autoafirmação, questionamento. O domínio de categorias de maior nível de abstração, entre as quais a categoria temporal, possibilita a discriminação mais clara dos limites de sua autonomia e de sua dependência, acrescida de um debate de valores. Idade adulta- apesar de todas as transformações ocorridas nas fases anteriores, o adulto reconhece como o mesmo e único ser: reconhece suas necessidades, possibilidades e limitações, seus sentimentos e valores, assume escolhas em decorrência de seus valores. Há um equilíbrio entre "estar centrado em si" e "estar centrado no outro".

Infere-se que tanto na adolescência quanto na vida adulta o educando se reconhece e valoriza sua autonomia, algo que precisa ser considerado pelo educador, pois a afetividade está nesse respeito à curiosidade, à identidade, à autonomia e às necessidades do educando, independente da fase da vida. Faz-se necessário compreender que a dimensão afetiva no processo educacional requer também considerar os limites, pois "os limites que facilitam o processo de ensino aprendizagem, garantindo o bem-estar de todos os envolvidos são também uma expressão de afetividade" (Mahoney \& Almeida, 2005, p. 24).

\section{A Força do Afeto no Processo de Alfabetização de Jovens e Adultos}

A Educação de Jovens e Adultos (EJA) é uma modalidade de ensino da Educação Básica destinada a alunos que estão na faixa etária acima daquela considerada própria para a conclusão do Ensino Fundamental ou Ensino Médio (Brasil, 2000).

O índice de reprovação e a evasão escolar ao longo dos anos têm contribuído para que a EJA continue sendo a oportunidade para as pessoas que não concluíram a educação básica em idade dita como regular, possam finalizar seus estudos (Souza, 2010). Gadotti e Romão (2011, p. 143) explanam:

A modalidade da EJA não deve ser entendida como uma reposição da escolaridade perdida [...] deve, sim, construir uma identidade própria, sem concessões à qualidade de ensino e propiciando uma terminalidade e acesso a certificados equivalentes ao ensino regular. 
Segundo a Constituição Federal de 1988 é garantido o acesso de jovens e adultos à educação. O inciso I do art. 208 determina ser dever do Estado garantir a Educação Básica de forma obrigatória e gratuita dos 4 aos 17 anos, assegurando também, a oferta gratuita para todos os que não tiverem acesso na idade própria (Brasil, 1988).

A Lei de Diretrizes e Bases da Educação Nacional (LDB), Lei n.o 9.394/96, dispõe também sobre a Educação de Jovens e Adultos. Em seu artigo 37, a lei define que o poder público tem a responsabilidade de estimular, viabilizar o acesso e a permanência de jovens e adultos na escola.

Art. 37o. A educação de jovens e adultos será destinada àqueles que não tiveram acesso ou continuidade de estudos no ensino fundamental e médio na idade própria.

$\S 10$. Os sistemas de ensino assegurarão gratuitamente aos jovens e aos adultos, que não puderam efetuar os estudos na idade regular, oportunidades educacionais apropriadas, consideradas as características do alunado, seus interesses, condições de vida e de trabalho, mediante cursos e exames.

§ 2o. O Poder Público viabilizará e estimulará o acesso e a permanência do trabalhador na escola, mediante ações integradas e complementares entre si.

O afastamento temporário da escola, nem sempre está ligado à vontade de interromper os estudos, por vezes os motivos podem ser outros, como falta de condições de transporte, ingressar em um emprego ou uma gravidez indesejada. E a escola precisa estar em constante trabalho para impedir ou amenizar a desistência dos educandos diante desses empecilhos (Lima Junior \& Kashiba, 2012).

Ao retornar ao âmbito escolar, o que eles buscam é o acolhimento, um ambiente onde eles possam interagir de acordo com suas diversidades e histórias (Lima Junior \& Kashiba, 2012). Uma característica da EJA é a diversidade dos educandos com relação à idade e nível de escolarização. Os autores Jardilino e Araújo (2014, p. 181) citam essa diversidade:

[...] verificamos uma nova composição das turmas da EJA: antes formadas quase exclusivamente por adultos que se afastaram da escola, hoje se configuram como espaços prioritariamente ocupados por jovens que, em sua maioria, não se afastaram da escola. Neste momento em que a educação se torna universal, acessível a todos, deparamo-nos com a presença majoritária de jovens excluídos da sala de aula regular, que buscam a EJA ou para ela são encaminhados pelo próprio sistema de ensino.

$\mathrm{O}$ ambiente e perfis dos educandos frequentadores da EJA, não são compostos apenas por indivíduos que passaram determinado tempo fora da sala de aula. Com o passar dos anos foi observado um aumento no número de jovens provindos do Ensino Fundamental e Médio que ao ingressar no mercado de trabalho optam pela continuidade dos estudos nessa modalidade (Jardilino \& Araújo, 2014).

Jardilino e Araújo (2014) ressaltam que a presença cada vez maior destes jovens na EJA tem sido identificada em todas as regiões do Brasil. Formar cidadãos críticos é algo complicado atualmente. Principalmente o aluno oriundo da educação de jovens e adultos, um sistema reduzido de disciplinas e tempo hábil de aplicação de conceitos fundamentais para aprendizagem crítica de um indivíduo.

Os adultos são sensíveis a estímulos de natureza externa, mas são os fatores de ordem interna como satisfação, autoestima e qualidade de vida que motivam o adulto para a aprendizagem (Ferreira, 2008). Segundo Paulo Freire, trata-se de ensinar o adulto a aprender a ler a realidade para, em seguida, transformá-la (Freire, 2002).

A sala de aula da EJA é um lugar diversificado, construído a partir da heterogeneidade dos alunos, baseando-se nas experiências, idades e valores que passam a serem partilhados através das relações ali presentes, ou seja, um espaço de formação humana que é desenvolvido no processo de ensino aprendizagem vinculado à afetividade. Referente a sala de aula, Leite (2012, p. 84) relata que: 
[...] o ambiente de sala de aula deve ser planejado de forma a garantir todas as condições possíveis no sentido de que as experiências aí vivenciadas produzam impactos afetivos positivos, o que aumentará a chance de o aluno continuar o seu processo escolar

A Educação de Jovens e Adultos exige um cuidado maior no planejamento das condições concretas de ensino, no sentido de garantir um ambiente afetivamente favorável para os alunos, visando a criação de vínculos de "aproximação" com os conteúdos e práticas desenvolvidas. Tanto os jovens quanto os adultos que frequentam as salas de alfabetização da EJA apresentam um aspecto comum: quase todos são marcados por uma história de exclusão vivenciada em uma escola convencional, durante a infância ou adolescência. É comum o relato de alunos apontando que tal situação foi determinada por condições econômicas e sociais desfavoráveis: nos adultos é constante a interrupção da vida escolar pela necessidade de a criança ajudar os pais na agricultura, situação que, geralmente, foi agravada pela grande distância entre a residência e a escola ou pela ausência de um sistema de transporte na época.

Por conta dessa realidade, o aluno da EJA, ao tentar reatar o vínculo interrompido, não pode encontrar um ambiente escolar que continue produzindo impactos afetivos negativos; ao contrário, o ambiente de sala de aula deve ser planejado de forma a garantir todas as condições possíveis no sentido de que as experiências vivenciadas produzam impactos afetivos positivos, o que aumentará a chance de o aluno continuar o seu processo escolar.

Nesse pressuposto, percebe-se que a afetividade e o diálogo se apresentam como importantes aliados da prática docente atuando como ferramentas de aproximação e conquista na relação professor e aluno. Dessa maneira é possível afirmar que a prática de alfabetizar fica mais prazerosa e motivadora, quando o educador transmite segurança para vivenciarem o novo âmbito escolar e assim, aprender significativamente.

O diálogo aliado a afetividade possibilitará o professor a conhecer as singularidades de cada um, mediante o interesse de comunicação tanto do professor, quanto dos alunos no processo de alfabetização. Freire (1996, p. 43), afirma que "O educador que escuta aprende a difícil lição de transformar o seu discurso, às vezes necessário, ao aluno, em uma fala com ele". Dessa forma, o diálogo aliado a afetividade contribui efetivamente para uma boa relação dos sujeitos envolvidos e do objeto de estudo.

Freire (1996) relata que além da afetividade é necessário a realização de um trabalho alfabetizador com o uso de atividades integradoras, que estimulem a curiosidade, o raciocínio e a coletividade entre os participantes, a fim de gerar resultados significativos diante das necessidades de aprendizagem de cada um dos discentes. Freire (1996, p. 90) ainda relata que:

É preciso, por outro lado, reinsistir em que não se pense que a prática educativa vivida com afetividade e alegria, prescinda da formação científica séria e da clareza política dos educadores ou educadoras. A prática educativa é tudo isso: afetividade, alegria, capacidade científica, domínio técnico a serviço da mudança ou, lamentavelmente, da permanência do hoje

Infere-se então que, o trabalho docente não se detém apenas a uma categoria e sim a diversas qualidades aliadas para a atuação no ambiente de sala de aula. No qual, por um lado o ser humano afetuoso que cuida, zela, educa com satisfação e, por outro a figura do profissional que precisa atuar com a responsabilidade de trabalhar os conteúdos curriculares, dos quais os educandos precisam para seu crescimento intelectual e cognitivo.

Ferreiro e Teberosky (1986), discutem sobre os períodos da psicogênese da língua escrita, durante o processo de alfabetização. Estes períodos são denominados de pré-silábico, silábico, silábico-alfabético e alfabético. No período présilábico o indivíduo ainda não consegue diferenciar símbolos de letras e números, escrevendo aleatoriamente, com rabiscos, desenhos ou outras formas, sem sentido de leitura. Cabendo ao professor como mediador da aprendizagem utilizar-se de recursos estimulantes, aliados ao afeto e amorosidade em busca dos avanços necessários destes aspectos cognitivos. Sobre o 
período silábico, as autoras afirmam que o indivíduo começa a utilizar letras para escrever, já com fonetização da escrita, passando por uma transição inicial, numa composição ainda não planejada, e já com apontamentos de uma pauta sonora. Nesse período, a intervenção do professor deve partir das habilidades já existentes, para que ocorra novas aprendizagens no intuito de avançar a caminho do próximo período, o silábico alfabético.

No período silábico-alfabético, o indivíduo inicia uma escrita com o uso de sílabas e alia esses pedaços de palavras ao som da voz pronunciada, já estando quase alfabetizada. Para concluir o processo de alfabetização o educando alcança o período alfabético, quando a mesma consegue escrever com sentido real de leitura, fazendo seus próprios planejamentos de escrita, necessitando apenas de um ajuste na ortografia, especialmente das palavras complexas (Ferreiro; Teberosky, 1986)

$\mathrm{O}$ educando em processo de aprendizagem necessita de materiais concretos como recursos adequados e que possibilitem os desenvolvimentos de cada etapa. "A abrangência de seu objeto de estudo sugere que a educação deve ter por meta não somente o desenvolvimento intelectual, mas a pessoa como um todo" (Wallon, apud Galvão, 1995, p.80). O educador ao iniciar com uma turma de alfabetização, deve necessariamente fazer uma sondagem dos conhecimentos prévios de cada educando, buscando conhecer como pessoa seus alunos de forma mais aproximada, diante de suas habilidades e necessidades. É a partir desse momento, que o professor desenvolverá materiais necessários para seguir no seu planejamento, buscando a contemplação de um trabalho voltado ao aprendizado significativo para a formação do sujeito.

O professor, se configura como um mediador do processo de aprendizagem e desenvolvimento, uma figura essencial para êxito na formação, principalmente na construção da subjetividade para a cidadania dos seus educandos, como ser humano pertencente a um contexto sociocultural. Freire (1996, p.43), explana que:

A professora democrática, coerente, competente, que testemunha seu gosto de vida, sua esperança no mundo melhor, que atesta sua capacidade de luta, seu respeito às diferenças, sabe cada vez mais o valor que tem para a modificação da realidade, a maneira consistente com que vive sua presença no mundo, de que sua experiência na escola é apenas um momento, mas um momento importante que precisa de ser autenticamente vivido

Percebe-se que o diálogo e o emprego da afetividade na relação professor aluno, como os caminhos mais favoráveis ao aprendizado significativo, no qual, o ato de ensinar é uma troca entre os saberes dos educandos, com os saberes do docente, que atua como uma figura mediadora desse aprendizado mútuo diariamente no contexto escolar.

\section{Considerações Finais}

Percebe-se que as relações afetivas que ocorrem dentro do contexto educacional são fundamentais para o conhecimento, pois a partilha de saberes implica na interação entre os sujeitos. Como explica Freire (1996), a educação ultrapassa os conteúdos, métodos e técnicas porque enfatiza, principalmente, a relação professor-aluno, em que um tem a possibilidade de aprender com o outro, ou seja, "não há docência sem discência [...]. Quem ensina aprende ao ensinar e quem aprende ensina ao aprender" (Freire, 1996, p. 12).

Ser um educador amável, trabalhar com apreço, dedicação e querer bem aos alunos, não implica em dizer que o professor esteja desenvolvendo suas aulas sem a preocupação de desenvolver no discente o conhecimento, a curiosidade, a motivação para aprender ou de torna-lo um ser crítico, questionador, lutador dos seus direitos. Significa que sua prática aliada a afetividade se complementa mutuamente para uma interação diversificada entre saberes e fazeres, diante do objeto de estudo proposto em sala.

Wallon (1972) procurou conceber a afetividade como a chave para o crescimento e a formação da personalidade do indivíduo. A sua teoria psicogenética é, na verdade uma teoria do sujeito, da sua condição biológica a uma ascensão ontológica racional tipicamente identificada com a condição humana. 
Infere-se, portanto, que as possibilidades de conter a evasão por meio da afetividade são de grande relevância, visto que a relação do professor com o aluno é fundamental no processo de ensino e aprendizagem, principalmente por se tratar de alunos com históricos de cansaço, de discriminação e interrupção de seus estudos. Outro fator relevante são as práticas pedagógicas que precisam estar em consonância com a realidade do educando, para que o mesmo se sinta inserido naquele contexto, facilitando o processo de ensino.

\section{Referências}

Almeida, L. R \& Mahoney, A. A. (2007). Afetividade e aprendizagem: contribuições de Henri Wallon. Edições Loyola.

Brasil. Ministério da Educação. (1996). Lei de Diretrizes e Bases da Educação Nacional (LDB) 9.394/96, de 20 de dezembro de 1996, Brasília.

Brasil. Ministério da Educação. (2000ª). Parâmetros Curriculares Nacionais, Brasília.

Codo, W., \& Gazzotti, A. A. (1999). Trabalho e Afetividade. In: CODO, W. (coord.) Educação, Carinho e Trabalho. Petrópolis-RJ: Vozes.

Freire, P. (1996). Pedagogia da Autonomia: saberes necessários à prática educativa. Paz e Terra.

Ferreira, A. M. F. (2008). A Análise digital de vídeo e software exploratório no ensino da Física. Dissertação (Mestrado em Ensino da Física e da Química) Faculdade de Ciências e Tecnologia, Universidade Nova de Lisboa, Lisboa.

Ferreiro, E., \& Teberosky, A. (1986). A psicogênese da língua escrita. Artes Médicas.

Gadotti, M., \& Romão, J. E. (2011). Educação de Jovens e Adultos: teoria, prática e proposta. Cortez.

Galvão, I. (1995). Henri Wallon: uma concepção dialética do desenvolvimento infantil/Izabel Galvão. - Petrópolis, Educação e conhecimento. RJ.

Gil, A. C. (2002). Como Elaborar Projetos de Pesquisa. (4a ed.), Atlas.

Jardilino, J. L., \& Araújo, R. B. (2014). Educação de Jovens e Adultos sujeitos saberes e práticas. Cortez.

Jarvis, P. (2013). Aprendendo a ser uma pessoa na sociedade: aprendendo a ser eu. In: ILLERIS, Knud. Teorias Contemporâneas da Aprendizagem. trad. Ronaldo Catado Costa. Penso, p.35-43.

Leite, S. A. S. (2012). Afetividade nas práticas pedagógicas. Temas em Psicologia, 20(2), 355-368.

Lima Junior, S., \& Kashiba, S. A. (2012). EJA - Educação de Jovens e Adultos: uma proposta desafiadora e articulada de ensinar Química. In: Encontro Nacional De Ensino De Química, 16; Encontro De Educação Química Da Bahia, 10. 2012, Salvador. Anais... Salvador: ENEQ.

Luck, H., \& Carneiro, D. G. (1985). Desenvolvimento afetivo na escola: promoção, mediação e avaliação. (2a ed.), Vozes.

Lüdke, M., \& André, M. (1986). A pesquisa em educação: abordagens qualitativas. EPU.

Mahoney, A. A., \& Almeida, L. R. (2005). Afetividade e processo ensino-aprendizagem: contribuições de Henri Wallon. Psicologia da educação, 20.

Souza, I. M. (2010). Fracasso Escolar e Interação Professor-Aluno. Wak, 2010.

Thomaz, L \& Oliveira, R. C. (2009). A educação $e$ a formação do cidadão crítico, autônomo e participativo. http://www.diaadiaeducacao.pr.gov.br/portals/pde/arquivos/1709-8.pdf.

Vieira, R. M. S. (2004). Afetividade e aprendizagem. Monografia (Especialização em Psicopedagogia) - Universidade Candido Mendes

Wallon, H. (1972). As origens do caráter na criança. Difel.

Wallon, H. (1973/1975). A psicologia genética. Trad. Ana Ra. In. Psicologia e educação da infância. Estampa (coletânea). 